\title{
Knowledge Dimension in Business Process Modeling
}

\author{
Ligita Businska and Marite Kirikova \\ Faculty of Computer Science and Information Technology, \\ Riga Technical Univesity, Latvia \\ \{ligita.businska, marite.kirikova\}@rtu.1v
}

\begin{abstract}
Various business process modeling notations give an opportunity to include elements that belong to different enterprise architecture models in the business process representation. Each model that relates to the business process via its elements can be viewed as a dimension of the business process. Thus the organizational structure model (performer model), goal model, data model, location model, and other models represent a particular dimension of the business process. One of the dimensions that have not yet evolved into a model, which could be easily related to the business process, is knowledge dimension. The paper presents knowledge state transition model rooted into the notion of knowledge code, analyses knowledge representation capabilities of existing business process modeling languages, and proposes a business process activity template, which includes internal and external representations of knowledge dimension. The template helps to clarify several issues with respect to knowledge dimension of business process models and to move forward towards the business process modeling language that can incorporate all modes of knowledge included in knowledge state transition model.
\end{abstract}

Keywords: data, information, knowledge, business process model.

\section{Introduction}

The period of distrust in business process model based approaches due to unsuccessful re-engineering efforts, which took place in the previous century, is over; and business process modeling again becomes an important topic in scientific literature [1-4]. However, it is worth to remember that business process engineering has to be a holistic approach and take into consideration various aspects or dimensions of the business system, including organizational and individual knowledge [1-5].

While importance of knowledge dimension is well recognized, there is no clear theoretical background and successful practical experiments of inclusion of this dimension in business process modeling languages. In such languages as IDEF0, IDEF3, EPC diagrams in ARIS tool, GRAPES BM in GRADE tool, UML 2.0 activity diagram, and BPMN 2.0 data, information and material flows are often represented by the same symbols and without any unambiguous definitions of the concepts. On the other hand, knowledge modeling languages (KMDL, GPO-WM, PROMOTE, and RAD) allow to model knowledge, but do not address process logic to full extent and 
thus there is no possibility to represent data $[6,7]$. Currently, from the point of view of various ways how data, information, and knowledge are used in organizations, the following issues are not yet fully supported in any of the above-mentioned business process modeling and knowledge modeling languages:

- Possibility to separate information and data during business process modeling

- Opportunity to identify the owner of data, information, and knowledge

- Possibility to identify, plan, and manage knowledge of the role required for participating in a particular activity and linking this knowledge to the organizational competence model

- Possibility to evaluate the amount of lost organizational knowledge if a person - owner of knowledge - leaves the organization, i.e., to identify which tacit knowledge in which cases should be transformed into explicit knowledge, such as documents, rules, systems, etc.

- Opportunity to improve understanding about the knowledge usefulness, validity, and relevance for particular activities in a process

- Opportunity to enable competence requirements management and proactive training based on a process reengineering impact analysis

The goal of this paper is to provide theoretically sound representation of the knowledge dimension that would give an opportunity to support above-mentioned issues in business process modeling. We aim at obtaining new knowledge helpful for developing modeling languages that could handle all relevant aspects related to knowledge dimension.

We have already tried to address knowledge dimension by using BPMN notation in our previous work [6]. This lead to the introduction of specific symbols for data, information and knowledge objects. Experiments with the notation revealed that the relationship between the phenomena behind the symbols is somewhat unclear in the modeling process. Therefore, in this paper, we focus on analysis of this relationship by investigating intersection of modern information theory assumptions and knowledge management definitions of information and knowledge.

In Section 2, we ponder over the terms data, information, and knowledge and come to the conclusion that the use of information codes as a supplementary term helps to clarify relationship between previous three terms. The state transition model of knowledge, which is taken as a theoretical basis for inclusion of knowledge dimension in business process model, is represented in this section, too. We use all four terms (data, information, knowledge, and information code) to define information interaction in homogenous and heterogeneous environments. In Section 3 , we analyze existing business process modeling languages in the context of information interaction. In Section 4 , the template of a business process activity with visible knowledge dimension is proposed and an example of its use is represented. In Section 5, pros and cons of the proposed approach are discussed.

\section{Constituents of Knowledge Dimension}

Data, information, and knowledge are concepts that are widely used in various fields of human activities. Their meaning is discussed in various fields of research since ancient times. Despite of numerous research works and scientific theories on interpretation of data, information, and knowledge in psychology, epistemology, 
social science, philosophy, cognitive science, and information theory; these terms are still used intuitively and often lack explicit unified definition within the areas of research. Most often data are associated to databases and knowledge is related to human beings, while information is attributed to both - databases and human beings. Uncertainty exists not only in definitions, but also in the practical use of the concepts. Usually in representation of flows between activities in existing languages of business process modeling do not distinguish between definitions of data, information, and knowledge and do not provide specific symbols for their representation in business process model [6]. Let us consider a business case when a seller who works with a cash register perceives barcodes and the data on the receipts just as data without certain meaning. However, for a commodity researcher this data provides meaningful information on goods; and processing of this information brings knowledge about sales volumes. In another case, a bank employee uses several information systems (IS) with different level of intelligence: without data interpretation, with data interpretation, and with ability to create new knowledge. Here it should be possible to distinguish between different types of inputs and outputs according to the level of intelligence of the system and to identify whether the bank employee has knowledge that enables him/her to understand and interpret data provided by the system. One more case that shows the difference between information and knowledge flows is situation where bank employee increases knowledge and speeds up client servicing when he/she tries to remember which products were corresponding to client goals; but this information about the goals of a particular client becomes insignificant when the next client comes to the desk. Thus, information flow appears when the bank employee remembers it temporarily and does not transform it into knowledge. Alternatively, the knowledge flow is significant if the bank employee accumulates information in order to improve his/her decision-making ability. From abovementioned cases, we can see that it is essential to understand what exactly (data, information, or knowledge) is transferred between the activities and how this could be represented separately in the process models.

In this paper, we do not discuss various interpretations of the above-mentioned terms deeply $[8,9,10,11,12]$. We focus on the relationship between data, information, and knowledge and rely upon the following observations and assumptions:

- Knowledge is located in the knowledge holder (natural or artificial)

- Knowledge in the knowledge holder (e.g., human brain) has a particular structure that may be regarded as a "mental model". The "mental model" can be natural or artificial, tacit and externalized, implicit and explicit

- Any business process involves a knowledge process which is performed by a natural or artificial knowledge holder

- If several knowledge holders are involved in the business process - data, information and knowledge exchange between them is possible. This exchange differs from the exchange of other substances as it is asymmetric: The amount of given information may differ from the amount of received information; and the knowledge holder does not lose knowledge by giving information based on this knowledge.

To obtain a holistic and at least semi-formal view of the relationship between data, information, and knowledge we use theory that shows that in information exchange a 
substance called 'information codes' is involved [8], i.e., information exchange is accomplished via information codes.

Suppose the knowledge holder (object $O_{1}$ provides information codes $T_{l}$ to another knowledge holder (object $\mathrm{O}_{2}$ ). The state transition in $\mathrm{O}_{2}$, which receives this information, is illustrated in Fig. 1. In the first phase, the object $\mathrm{O}_{2}$ receives particular information code $I c_{l}$. To perceive the code the object needs a particular "linguistic device" that can recognize the code (e.g., if the code is information in English, it can be recognized if there is a "device" that can handle English). The received code is transformed into data $\Delta d$. Thus, data are functional values of information codes, which correspond to new parameters of object state obtained in interaction with another object.

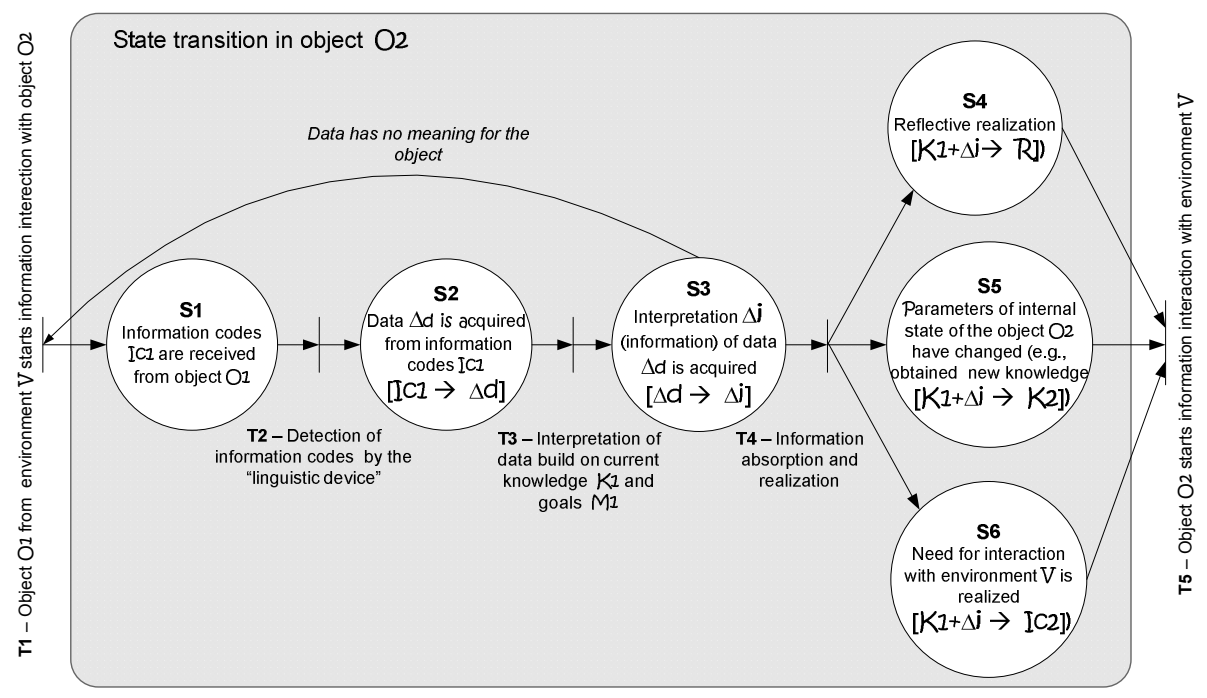

Fig. 1. State transition in the knowledge owner when it receives information codes

In the next phase, object $O_{2}$ defines the meaning of obtained data $\Delta d$. This is a subjective interpretation of $\Delta i$ by current knowledge of $K_{1}$ of $\mathrm{O}_{2}$ taking into consideration $M_{1}$ - the set of its current needs or goals. According to [9] structured and processed data is information that is time dependent (relevant only in a given point of time) and correct with respect to the processed data set. In general, the amount of received information can be calculated as a difference between knowledge obtained after data interpretation and knowledge possessed before the interaction with object $O_{1}: \Delta i=Z_{1}-Z_{2}$. It can be regarded as a measure of reduction of uncertainty for choosing actions in order to achieve particular goals $M_{l}[13]$.

Information exists from the moment the data is interpreted until the moment when the information has been absorbed or included in the mental model of the object. The content or structure of the mental model (including procedural and declarative knowledge, which is stored in it) can be changed as the result of information absorption. 
Finally, recognition of obtained information $\Delta i$ takes place. The implementation can lead to changes of internal state parameters of object $\mathrm{O}_{2}$ or/and to the next cycle of interaction with the environment. Several overlapping options of implementation can take place: (1) a reflective action: $K_{l}+\Delta i \rightarrow R$; (2) object $O_{2}$ delivers appropriate set of information codes: $K_{l}+\Delta i \rightarrow I c_{2}$ in case of starting the next cycle of interaction with object(-s) from its environment; (3) object's mental model (internal state) can change under certain conditions when obtaining new knowledge: $K_{1}+\Delta i \rightarrow K_{2}$. According to [14] knowledge is reasoning about data that is stored in object's "mental model" in order to promote action, problem solving, decision-making, learning, and teaching. Knowledge is a higher organizational level of data that allows their specific interpretation. Requirements to data organization level can vary from a simple grouping of the data to complicated data hyper-structures.

Thus according to [8] a single cycle of information interaction between object and its environment has three sequential phases: (1) the object receives information codes from its environment, (2) it interprets the obtained codes, and finally (3) it recognizes the information obtained by interpretation (reflects upon it, absorbes it, and/or puts it into the action). In Fig. 2 a simplified example with two objects (the process performer (analyst) and the document that includes interview protocols) is shown.

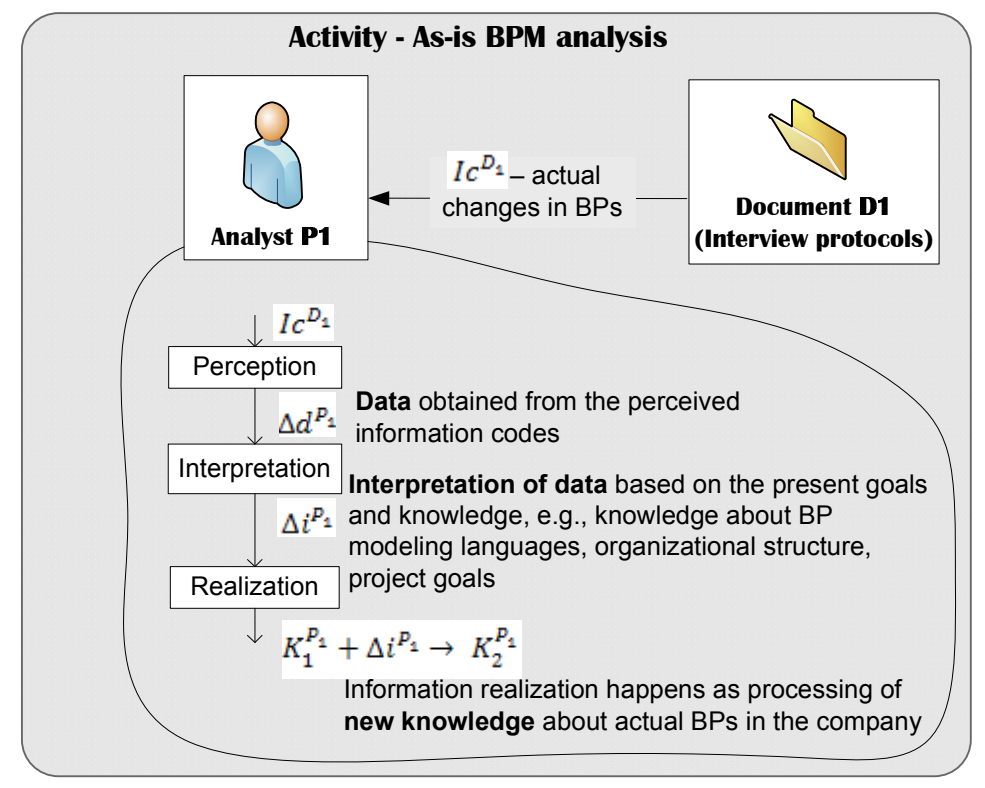

Fig. 2. A simplified example of an activity

In the above-given example the analyst performs the activity of analyzing as-is business process model that is described in Document D1. When reading this document, the analyst perceives information codes by his/her receptors and obtains certain set of data. In this stage, perceived data does not have any meaning for the analyst. According to above-mentioned information theory, perceived data are 
compared with the present goals/needs and background knowledge (e.g., PB modeling languages, organizational structure, project goals) of the analyst. As the result the subjective interpretation of data (or information) is obtained. Finally, the information is recognized by the analyst as new knowledge about actual business processes in the company. It means that the recognition process changes the mental model of the analyst (e.g., by enriching it with new links or nodes, reorganizing or generalizing existing structure, or adding new values for structure elements).

The performer of a business process can receive information codes in three different ways, namely, from human, from active artificial object, and from passive artificial object. Depending on the situation the interchange of information codes can take place in homogenous (human-human, IS-IS) or heterogeneous (human-IS, ISdocument, human-document) environments. In Fig. 3 and 4 internal changes in objects (knowledge holders) are illustrated. Fig. 3.A shows information code interchange and new knowledge (natural or artificial) development in homogenous environment (on the left: human-human and on the right: computer IS-IS). Fig. 3.B illustrates how natural or artificial knowledge holder interacts with the passive knowledge holder (document).
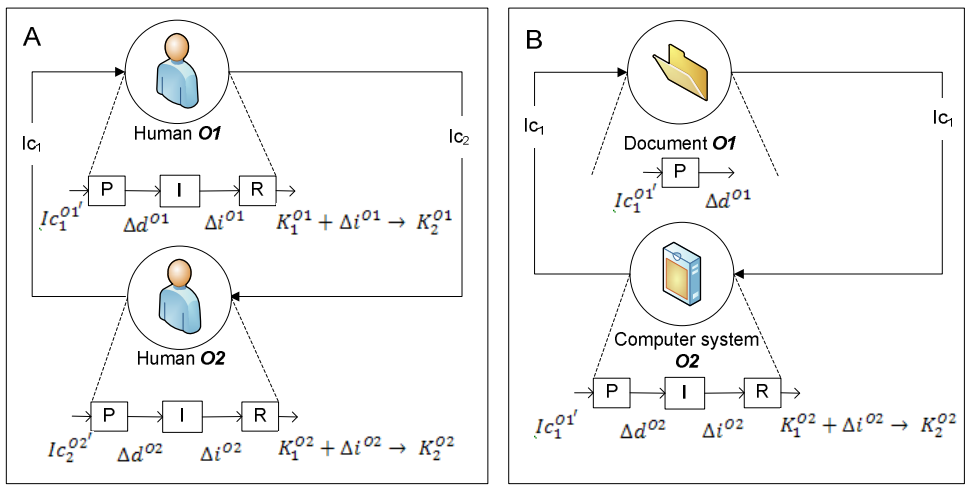

Fig. 3. Different types of information interaction. A: Information interaction in homogenous environments; B: Information interaction between active knowledge holders and passive knowledgeholders ( $\mathrm{P}$ - perception, I - interpretation, $\mathrm{R}$ - recognition)

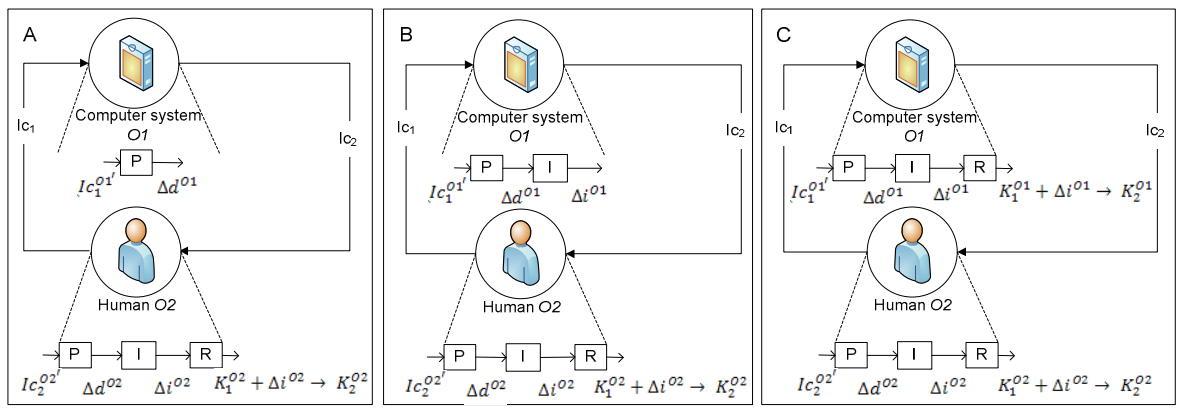

Fig. 4. Information interaction in heterogeneous environment (among active objects) ( $\mathrm{P}-$ perception, I - interpretation, $\mathrm{R}$ - recognition) 
Figure 4 illustrates heterogeneous environment with two different types of knowledge holders. The interchange and knowledge development can proceed differently depending on the level of intelligence of the IS (computer system): from the left to right: without data interpretation; with data interpretation only, and with learning ability.

The above analysis of information interaction shows that changes in knowledge are initiated by perception of particular information codes. Thus, for representing the knowledge dimension it would be necessary to show knowledge before and after perception of information codes as well as the coded information itself. The potential of contemporary business process modeling languages in this regard is examined in the next section.

\section{Information Exchange in Business Process Context}

In our previous work [6] we analyzed different attempts to include knowledge dimension in business process modeling and knowledge modeling languages and we proposed to integrate knowledge-oriented modeling language KMDL [15] and BPMN notation [15]. In this work three different objects were used: knowledge objects, information objects and data objects. However, further experiments with the integrated notation showed that it is difficult to distinguish between data and information objects. Theoretical issues discussed in the previous section clarify the reason behind this difficulty. It shows that data is an internal rather than the external phenomenon with respect to the knowledge holder; and interchange of perceivable knowledge is accomplished via information codes. None of the approaches analyzed in [6 and 7] took into consideration information codes and therefore they are not directly applicable for representation of knowledge dimension in the way it is described in the previous section. In particular, BPMN provides opportunity to model only information and data flow using the same modeling constructs $[6,15]$.

In the proposed approach, the main difference from existing notations is outlining the owner of the data, information, and knowledge, which can be a human or an artificial object. The processing of information codes occurs inside the actor, but in the model it is shown just as the result of the processing: obtained knowledge or received interpretation of data (information). Additionally, actors have a link to materialized or non-materialized knowledge, which is used as a resource for processing information codes.

Both business process modeling [6] and knowledge modeling [7] approaches concern the linkage between the business processes and knowledge. Since in practice, knowledge modeling languages are used less often than business process modeling languages; in this paper we mainly consider business process modeling languages in order to see how appropriate they are for inclusion of knowledge dimension. The following business process modeling languages were analyzed: GRAPES BM - in GRADE tool [17], EPC diagrams in ARIS [18], KMDL [19], IDEF 0 [20], UML 2.0 activity graphs [21], and BPMN 2.0 [16]. The languages were analyzed from the following two points of view (1) possibilities to represent data and knowledge (Table 1) and (2) possibilities to represent process logics (Table 2). Both views are important for representation of static and dynamic aspects of knowledge in individual knowledge holders and in the whole business process. 
The contents of Table 1 and Table 2 are based on the results obtained in the previous research $[6,7]$. In [6 and 7] we analyzed syntaxes and semantic of modeling languages in order to understand their data, information, knowledge interpretation and modeling capabilities. In addition, we illustrated the described differences of data, information, and knowledge representation by modeling the same business process in the selected modeling languages.

Table 1. Representation of inputs, outputs, and resources ( "_“ means "does not support”; “-/+”" means "somewhat supports"; "+" means "inclusion is possible"; "++" means "almost fully supports", and "+++" means "supports fully")

\begin{tabular}{l|cccccc}
\hline Criteria & GRAPES & EPC & IDEFO & KMDL & UML & BPMN \\
\hline Input/output [data] & + & +++ & + & - & + & ++ \\
Input/output [information] & + & +++ & + & + & + & ++ \\
Input/output [knowledge] & - & $+/-$ & - & +++ & - & - \\
Resource [knowledge] & - & - & - & - & - & - \\
Resource [human] & + & ++ & + & - & - & + \\
Resource [artificial] & + & + & + & - & - & + \\
Resource [data store] & + & + & - & - & + & + \\
\hline
\end{tabular}

Table 2. Representation of process logics ( "-“ means "does not support”; “-/+” means "somewhat supports"; "+" means "inclusion is possible"; "++" means "almost fully supports", and "+++" means "supports fully")

\begin{tabular}{l|cccccc}
\hline Criteria & GRAPES & EPC & IDEFO & KMDL & UML & BPMN \\
\hline Process management & $-/+$ & $-/+$ & + & - & $-/+$ & $-/+$ \\
Controls & $-/+$ & $-/+$ & + & - & $-/+$ & $-/+$ \\
Decision points & + & + & - & + & + & + \\
Control flows & + & ++ & - & + & ++ & +++ \\
Events & + & ++ & - & - & + & +++ \\
\hline
\end{tabular}

We can conclude that BPMN and ARIS EPC are more expressive for modeling process logic, decision points and control flows than other languages, while BPMN offers extended notation for control flow organization; and ARIS EPC is the most expressive in linkage of modeling dimensions (e.g., IS, products, organization, risks, and key performance indicators). Knowledge inclusion into the model is possible in KMDL and ARIS EPC, in the most convenient way data can be represented by UML activity diagram, and, for information flows representation, BPMN collaboration and choreography models can be used.

In Figure 5 a schematic comparison of above-mentioned notations and languages is given according to five business process modeling dimensions, namely: data, information, knowledge, material, and process. The diagrams show potential capabilities of the discussed notations or languages to represent particular business process modeling dimension. Results are presented in the interval from 0 to 4 , where 0 means that the notation does not provide any symbols for the particular dimension and 4 means that the notation has a considerable number of symbols for the particular dimension. 
From the point of view of knowledge dimension representation, the least feasible is IDEF0. Obviously, this language has to be modified in case it is taken as a basis for the representation of knowledge dimension. However, IDEF0 allows distinguishing between different kinds of the input flows (controls, inputs, and resources) that are important for extending process model with knowledge dimension. Therefore, it makes sense to examine a possibility to construct extended IDEF0 based form of process representation to see how appropriate the notation is for incorporating the knowledge dimension. IDEF0 based approach presented in this paper is one of the alternatives how to integrate data, information, and knowledge representation in the process model; and additional future research and experiments with other notations are needed to select the most appropriate modeling technique.
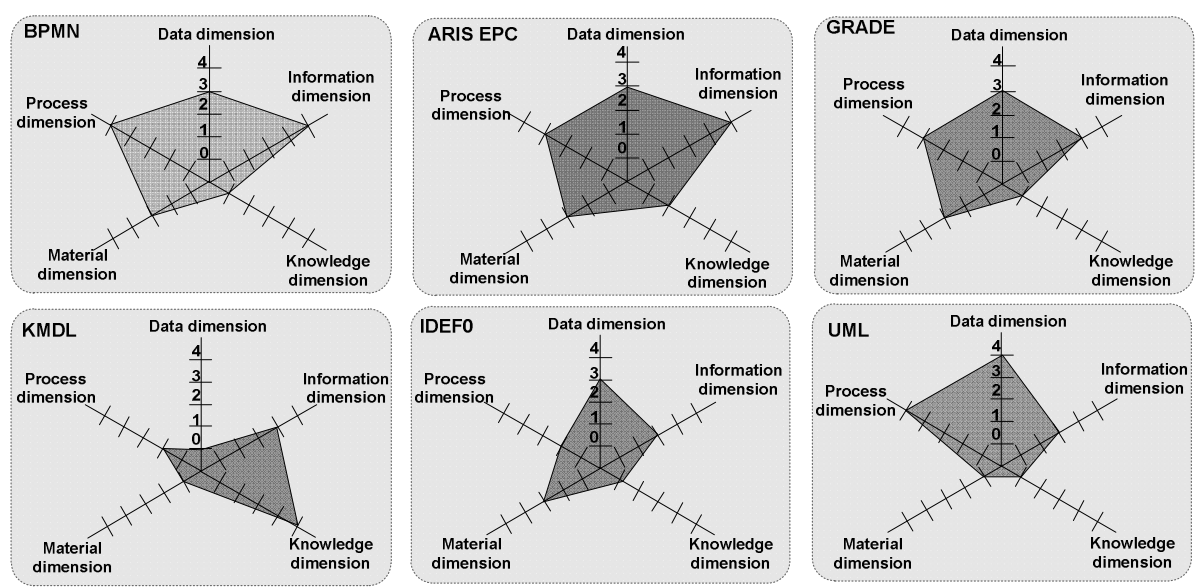

Fig. 5. Schematic comparison of process-oriented and knowledge-oriented languages and notations

\section{Transparent Representation of Knowledge Dimension}

In this section, we propose one of the approaches of representing business process activities with knowledge dimension. We strive to show the proposed ideas graphically. The representation is based on IDEF0 notation. Its purpose is to experimentally examine the applicability of IDEF0 for inclusion of knowledge dimension in business process model; and it should not yet be considered as a new business process modeling notation. IDEF0 was chosen as the basis for activity template, because it gives an opportunity to distinguish between controls (relates to knowledge holder's goals (see Section 2)), inputs/outputs (received and produced information codes), and resources (knowledge in the holder). However, since IDEF0 notation is weak in representing logic of the process, in our further research, we intend to combine it with other notations that give more tools for control and decision points modeling. The activity template and example of its use are represented in Fig. 6,7 and 8.

Each Activity (Fig. 6.A) corresponds to one of different combinations of interaction between human, computer systems, and documents as shown in Fig. 3-4. Social 
processes among performers inside the activity are not represented (Fig. 6.B). The activity template has the following attributes: Activity name, Performers of the activity (human or artificial (computer) system). For knowledge intensive activities there is an additional attribute Type with possible values Socialization, Externalization, Combination, and Internalization. Visually, these attributes and their values are positioned in the central part of the template. The central part is surrounded by four blocks that correspond to four types of knowledge, namely: control knowledge $K c$, input knowledge $K i$, output knowledge $K o$, and resource knowledge $K r$. This is knowledge that is inside the knowledge holders (natural and/or artificial) participating in the activity and can be referred to as tacit knowledge. Each block of the tacit knowledge can be linked to particular artifacts: input artifacts $I$, output artifacts $O$, resource artifacts $R$, and control artifacts $C$, which in essence are information codes perceived by tacit (natural or artificial) knowledge of the performers of the process. Each block $K c, K i$, Ko, and $K r$, of the template can be related to particular concepts of the representation of organizational "mental model", if such is maintained.

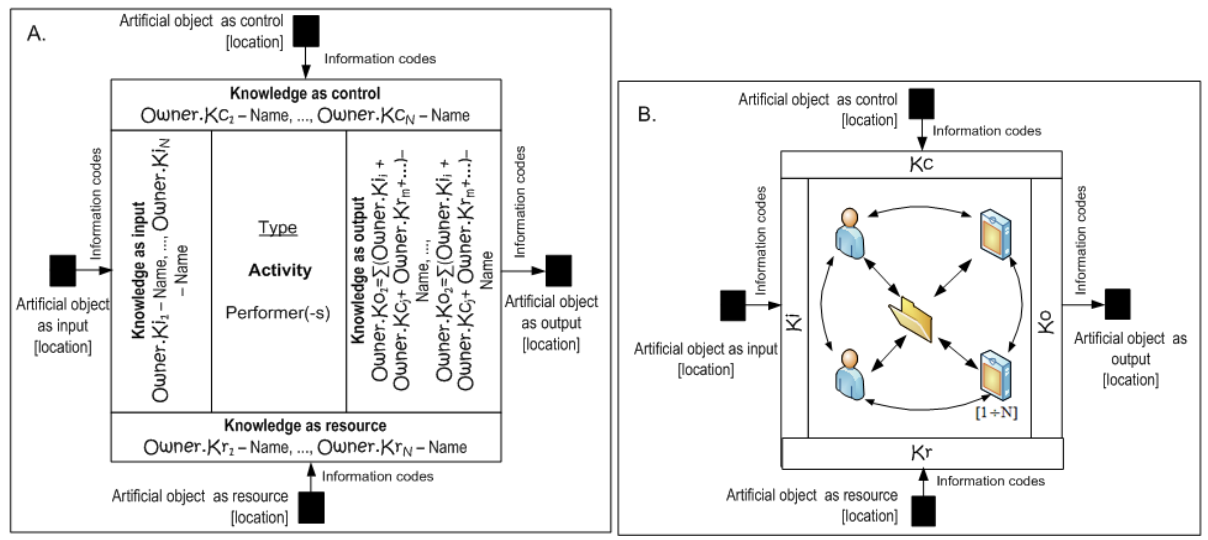

Fig. 6. Activity with a knowledge dimension: A: activity template; B: activity zoomed in (this information is not presented in the template)
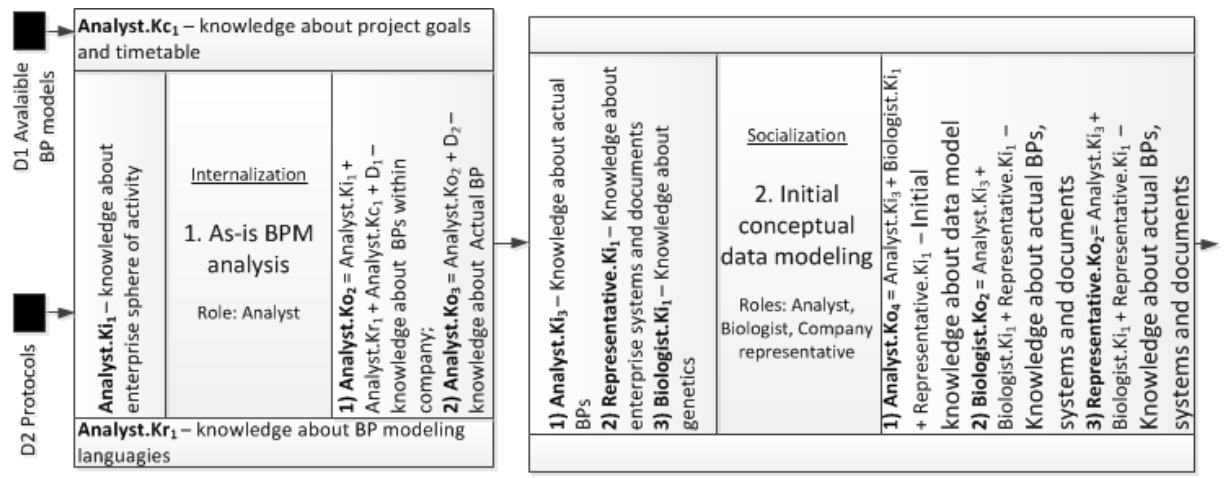

Fig. 7. Fragment of the business process model Development of logical data model of Bioinformatics Company represented by the template 
Table 3. Four types of knowledge: input, resource, control, and output

\begin{tabular}{|c|c|}
\hline 1. As-is BPM analysis & 2. Initial conceptual data modeling \\
\hline \multirow{7}{*}{$\begin{array}{l}\text { INPUT - Analyst's knowledge about the } \\
\text { enterprise domain of activity } \\
\left.(\text { Analyst.Ki })_{1}\right) \\
\text { RESOURCE - Analyst's knowledge } \\
\text { about BP modeling languages } \\
\text { (Analyst.Kr }{ }_{1} \text { ) } \\
\text { CONTROL - Analyst's knowledge } \\
\text { about the project goals and timetable } \\
\text { (Analyst.Kc }{ }_{1} \text { ) } \\
\text { OUTPUT - }\end{array}$} & \multirow{3}{*}{$\begin{array}{l}\text { INPUT - } \\
\text { 1) Analyst's knowledge about actual BPs } \\
\text { obtained in the previous activity } \\
\left(\text { Analyst.Ki } \mathbf{H}_{\mathbf{3}}\right)\end{array}$} \\
\hline & \\
\hline & \\
\hline & \multirow{2}{*}{$\begin{array}{l}\text { 2) Company representatives knowledge about } \\
\text { the enterprise systems and documents } \\
\text { (Representative. } \mathbf{K i}_{\mathbf{1}} \text { ) }\end{array}$} \\
\hline & \\
\hline & $\begin{array}{l}\text { 3) Biologist knowledge about genetics } \\
\left(\text { Biologist. } \mathbf{K i}_{\mathbf{1}}\right)\end{array}$ \\
\hline & OUTPUT - \\
\hline \multirow[t]{2}{*}{ 1) } & \\
\hline & $\begin{array}{l}\text { Biologist's knowledge about actual BPs, } \\
\text { systems and documents (obtained during } \\
\text { socialization activity) }\end{array}$ \\
\hline \multirow{4}{*}{$\begin{array}{l}\text { 2) Analyst's knowledge about actual } \\
\text { BPs is obtained based on the } \\
\text { combination of knowledge about } \\
\text { BPs and knowledge embedded in } \\
\text { Document } 2 \\
\text { (Analyst.Ko } \mathbf{K o}_{3}=\text { Analyst. } \mathbf{K o}_{2}+\mathbf{D}_{2} \text { ) }\end{array}$} & $\begin{array}{l}\left(\text { Biologist.Ko } \mathrm{Ko}_{2}=\text { Analyst. } \mathrm{Ki}_{3}+\right. \\
\left.\text { Biologist.Ki }{ }_{1}+\text { Representative. } \mathrm{Ki}_{4}\right)\end{array}$ \\
\hline & $\begin{array}{l}\text { Company representatives knowledge about } \\
\text { actual BPs, systems and documents }\end{array}$ \\
\hline & \\
\hline & $\begin{array}{l}\left(\text { Representative. } K o_{2}=\text { Analyst. } K \mathbf{i}_{3}+\right. \\
\left.\text { Biologist. } K \mathbf{i}_{1}+\text { Representative. } K \mathbf{i}_{4}\right)\end{array}$ \\
\hline
\end{tabular}

To illustrate the proposed template the fragment of a logical data model of Bioinformatics Company is illustrated (Fig. 7 and 8). The given fragment consists of two consecutive activities performed to create a logical data model of the Company. First, the analyst studies available documents. During this activity he/she perceives information codes that are embodied in the documents. Then the analyst together with the biologist and the company representative discusses knowledge obtained in the previous activity. This way they exchange information codes and each of them processes perceived codes inside his/her brains according to personal mental model and goals. As a result, they could extend their mental models with new data or, under certain conditions, obtain new knowledge. Figure 7 represents the business process model using the proposed activity template (see. Fig. 6.A). Additionally, Table 3 describes inputs, resources, controls, and outputs of the activities in detail.

Since currently our aim is not to establish a new business process notation, the main effort is put in reflecting knowledge dimension graphically. More studies and experiments are needed to determine the best way of the reflection. The main limitation of the proposed graphical representation is that it looks complex, especially, if the number of activities in the process model is increased. One of the solutions for reducing complexity of comprehension is developing appropriate modeling tool with 
embodied functionality to switch between different views of the process, e.g., process view and data/information/knowledge view. Pros and cons of the proposed approach are analyzed in Section 5 in more detail.

\section{Discussion of Proposed Approach and Conclusions}

To evaluate the proposed graphical notation, we consider the business process example in Fig. 8 and its representation using the proposed template (Fig. 9).

By comparing models in Fig. 8 and 9, it is possible to make some preliminary conclusions that are summarized in the Table 4. The table shows that the proposed approach opens a possibility to consider issues of organizational knowledge that cannot be included in conventional BPMN models. Nevertheless, the approach has several drawbacks related to representation of data stores, events, control flows, and decision points.

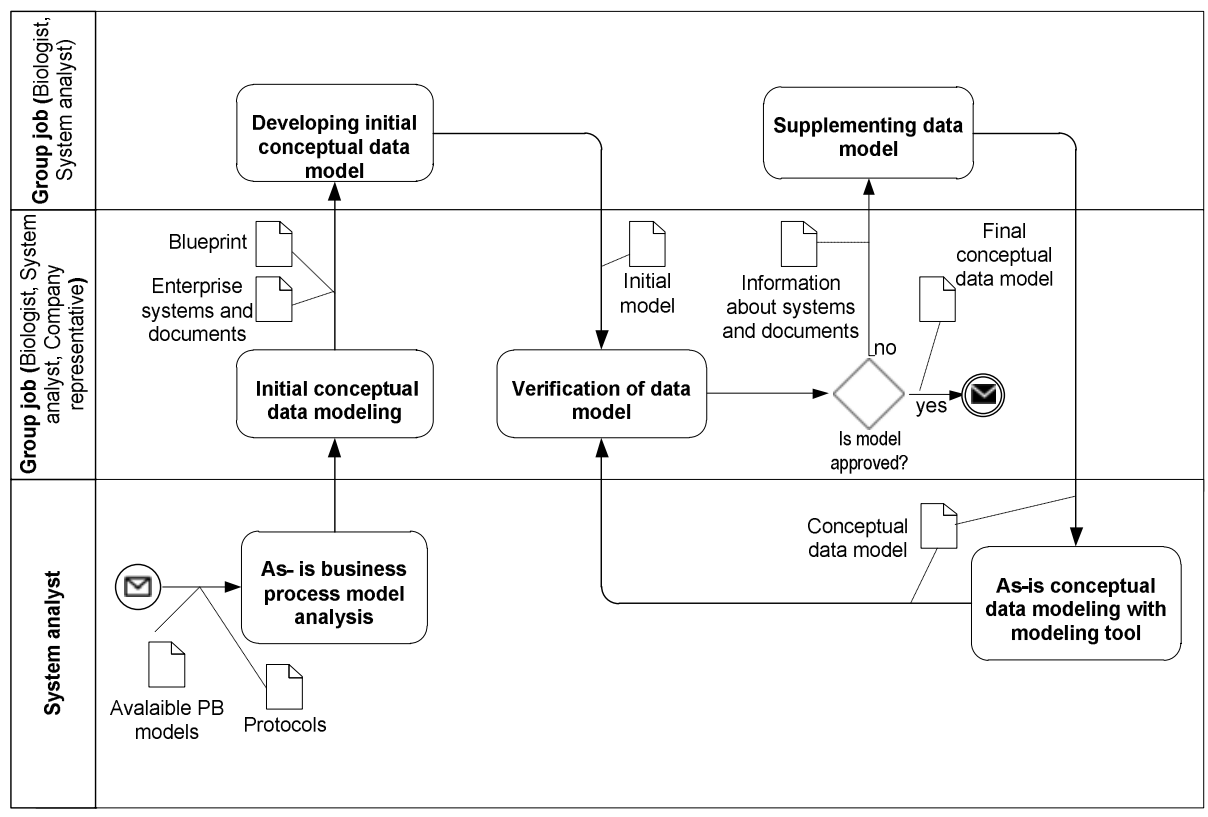

Fig. 8. Business process model developed in BPMN

In business process analysis, design, engineering, and reengineering, it is important to have a holistic view of the enterprise. Since organizational knowledge is an essential aspect of an enterprise, there is a need of transparent linkage between the business process model and organizational and individual knowledge. In order to achieve this transparency the paper proposes a new activity template that gives visual means to relate business process to organizational knowledge and to analyze knowledge circulation in a business process. The model presented in the paper is in its experimental stage. As discussed in Sections 4 and 5, it helps to deal with the following issues related to knowledge dimension of business process models: 

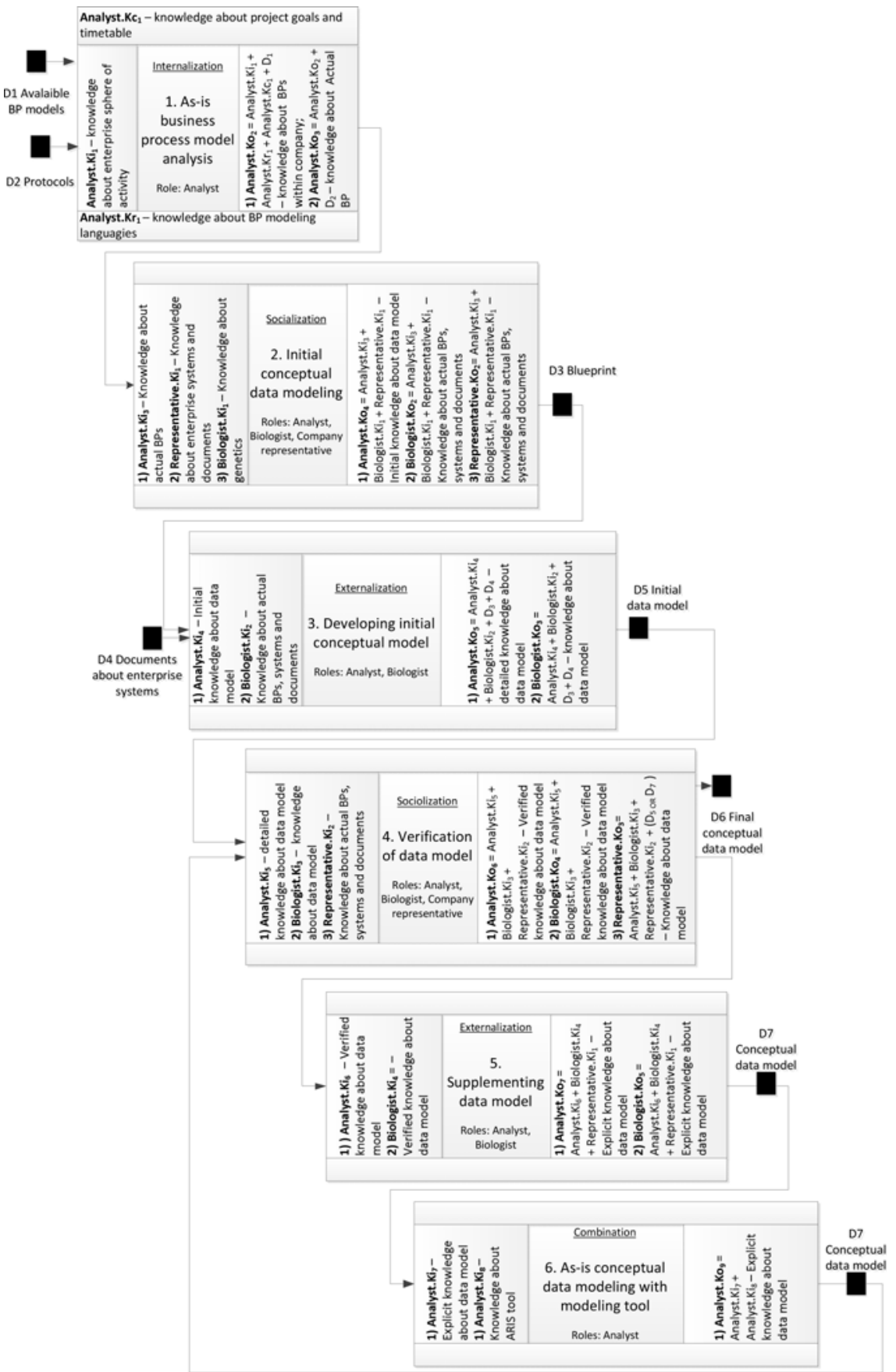

Fig. 9. Business process model developed according to proposed template 
Table 4. Comparison of business process representation in BPMN and using of the proposed template

\begin{tabular}{|c|c|c|c|}
\hline Criteria & 1 & 2 & Description \\
\hline \multicolumn{4}{|c|}{$\begin{array}{l}1-\mathrm{BPMN} \\
2 \text { - Proposed template }\end{array}$} \\
\hline $\begin{array}{l}\text { Input/output } \\
\text { [data] } \\
\text { Input/output } \\
\text { [information] } \\
\text { Input/output } \\
\text { [knowledge] }\end{array}$ & - & + & $\begin{array}{l}\text { Unlike in other modeling languages, in the proposed model } \\
\text { three flows are represented: information, knowledge, and data } \\
\text { flow. The proposed template strictly distinguishes between tacit } \\
\text { and explicit data, information, and knowledge. Artificial objects } \\
\text { are the holders of explicit or materialized data, information, and } \\
\text { knowledge; tacit data, information, and knowledge belonging to } \\
\text { the certain person and are modeled inside the activity }\end{array}$ \\
\hline $\begin{array}{l}\text { Resource } \\
\text { [knowledge] }\end{array}$ & - & + & $\begin{array}{l}\text { In the proposed representation of a concept 'knowledge as a } \\
\text { resource', which might be required for the role, is introduced. } \\
\text { Knowledge as a resource unlike other types of resources } \\
\text { (materials, technology) does not have depreciation, however } \\
\text { training curve needs to be taken into account (time is needed to } \\
\text { collect all required knowledge and skills). }\end{array}$ \\
\hline $\begin{array}{l}\text { Resource } \\
\text { [human] }\end{array}$ & & + & $\begin{array}{l}\text { It is possible to add process performer to each activity. } \\
\text { Knowledge is related to role (owner of knowledge) thus it is } \\
\text { possible to derive specific knowledge associated to each person, } \\
\text { as well as to trace how certain person obtains his/her knowledge } \\
\text { during the process execution. The utilization of knowledge } \\
\text { dimensions helps to plan the training and changes in required } \\
\text { competences and resources already during business process } \\
\text { modeling phase }\end{array}$ \\
\hline $\begin{array}{l}\text { Resource } \\
\text { [artificial] }\end{array}$ & - & + & $\begin{array}{l}\text { Resources, which are materialized and could be saved in } \\
\text { knowledge repository as several documents, instructions, or } \\
\text { books, are separated from the resources that are not } \\
\text { materialized, but can facilitate process completion. }\end{array}$ \\
\hline $\begin{array}{l}\text { Resource [data } \\
\text { store] }\end{array}$ & - & - & $\begin{array}{l}\text { Proposed template does not provide separate modeling } \\
\text { constructions for data store modeling }\end{array}$ \\
\hline $\begin{array}{l}\text { Knowledge } \\
\text { intensive process } \\
\text { type }\end{array}$ & - & + & $\begin{array}{l}\text { Each activity is defined as either knowledge intensive or not } \\
\text { knowledge intensive. In the template the knowledge conversion } \\
\text { type is the attribute of an activity. It could be useful for } \\
\text { improving knowledge sharing among process performers. }\end{array}$ \\
\hline $\begin{array}{l}\text { Process } \\
\text { management }\end{array}$ & + & + & Has no specific benefits to compare to BPMN \\
\hline Controls & + & + & Has no specific benefits to compare to BPMN \\
\hline $\begin{array}{l}\text { Control flows } \\
\text { Decision points } \\
\text { Events }\end{array}$ & $\begin{array}{l}+ \\
+ \\
+\end{array}$ & $\begin{array}{l}- \\
-\end{array}$ & $\begin{array}{l}\text { IDEF0 notation is not the most suitable for representing logic of } \\
\text { the process, therefore, it should be combined with other } \\
\text { notations that give more means for control and decision points } \\
\text { modeling }\end{array}$ \\
\hline
\end{tabular}


- It gives a possibility to separate information and data in the business process modeling

- It gives an opportunity to identify the owner of data, information, and knowledge

- It gives a possibility to identify, plan, and manage knowledge of the role required for participating in a particular activity and linking this knowledge to the organizational competence model, if such is maintained

- It gives a possibility to evaluate the amount of lost organizational knowledge if a person - owner of knowledge - leaves the organization, i.e., to identify which tacit knowledge in which cases should be transformed into explicit knowledge, such as documents, rules, systems, etc.

- It gives an opportunity to improve understanding about the knowledge usefulness, validity, and relevance for particular activities in a process

- It gives an opportunity to enable competence requirements management and proactive training based on a business process analysis

The main disadvantages of the proposed approach are (1) complexity of graphical representation of the activity template and (2) drawbacks of procedural representation inherited from IDEF0. Therefore, further research will aim to design the appropriate means for reduction of complexity of representation and enriching model with possibilities to model events, decision points, and control flows or, alternatively, to link the template to the conventional business process models.

\section{References}

1. Baimin, B.S., Zijun, H., Xiohua, G.: Knowledge process reengineering and implementation of enterprise knowledge management. In: International Conference on Information Management, Innovation Management and Industrial Engineering, pp. 23-26 (2010)

2. Wang, S.-B., Wang, Ch, Yang, J. Research on the reengineering of government business processes based on the environment of e-government. In: International Conference on EBusiness and E-Government, pp. 4503-4506 (2010)

3. Li, B.-Z., Liu, Y.: Organizational change pattern based on business process reengineering. In: International Conference on E-Business and E-Government, pp. 1193-1197 (2010)

4. Chalaris, I.E., Vlachopoulos, S.: Business Process Reengineering as a Modernizing Tool for the Public Administration- From Theory to Reality. In: Fourth Balkan Conference in Informatics, pp. 64-69 (2009)

5. Weicher, M., Chu, W.W., Lin, W.C., Le, V., Yu, D.: Business Process Reengineering: Analysis and Recommendations, http: / / www . netlib.com/bpr1.htm\#reenghr

6. Businska, L., Supulniece, I., Kirikova, M.: On data, information, and knowledge representation in business process models. In: The 20th International Conference on Information Systems Development (ISD 2011), Edinburgh, Scotland. Springer (2011)

7. Supulniece, I., Businska, L., Kirikova, M.: Towards Extending BPMN with the Knowledge Dimension. In: Bider, I., Halpin, T., Krogstie, J., Nurcan, S., Proper, E., Schmidt, R., Ukor, R. (eds.) BPMDS 2010 and EMMSAD 2010. LNBIP, vol. 50, pp. 6981. Springer, Heidelberg (2010) 
8. Янковский, С.Я.: Концепции общей теории информации. НиТ. Текущие публикации (2001), http://n-t.ru/tp/ng/oti03.html

9. Maier, R.: Knowledge management systems. Information and communication Technologies for knowledge management, 3rd edn. Springer, Heidelberg (2007)

10. Tiwana, A.: Knowledge Management Toolkit, The: Practical Techniques for Building a Knowledge Management System. Pearson Education (1999)

11. Beyon-Davies, P.B.: Significant threads: The nature of data. International Journal of Information Management 29, 170-188 (2009)

12. Francois, C. (ed.): International Encyclopedia of Systems and Cybernetics, 2nd edn. K.G. Saur, Munhen (2004)

13. Corning, P.A.: Control Information Theory: 'The missing link' in the science of cybernetics, Systems research and behavioral science. Syst. Res. 24, 297-311 (2007)

14. Beckman, T.: A methodology for knowledge management. In: IASTED International Conference on Artificial, Intelligence and Soft Computing (ASC 1997), Banff, Canada, pp. 29-32 (1997)

15. Gronau, N., Korf, R., Müller, C.: KMDL-Capturing, Analyzing and Improving Knowledge-Intensive Business Processes. Journal of Computer Science 4, 452-472 (2005)

16. Business Process Modeling Notation (BPMN), http: / / www . omg . org/spec/BPMN/2 . 0 / PDF

17. GRADE Business Modeling, Language Reference, Infologistik GmbH (1998)

18. ARIS Expert Paper, Business Process Design as the Basis for Compliance Management, Enterprise Architecture and Business Rules (2007)

19. Arbeitsbericht (umfangreiche Beschreibung) - KMDL® v2.2, http: / / www . kmal . de

20. IDEF0, http://www. idef. com/IDEF0.html

21. UML,

http: / /www.visual-paradigm.com/VPGallery/diagrams /

Activity.html 